Sulphur Well, a deposition of sulphur occurs at the positive pole. If therefore it is a desideratum to have sulphur in a nascent state on the skin, the arrangement proposed seems exceeding well calculated to effect the object in view, and to be much more efficient than simple immersion of the body in sulphur waters. I have of course no title to discuss the efficacy of the process from a therapeutic standpoint.

Professor Smithells forwarded at the same time the following supplementary report from Dr. Dawson :

The rationale of the electrolytic process by which sulphur is separated at the positive pole on electrolysis of the Harrogate sulphur waters is probably as follows. It is probable that part of the sulphur is present ne waters as free sulphuretted hydrogen, the remaiuder being present in the form of alkaline sulphides. (rhis of course leaves out of confreration present in the rom probable that a very. considerable quantity of the sulphur is present as of the sulpluretted lodrog is free; alkaline sulphides exist probably in the solution. On passing a current through the water from the Old Sulphur Well,
which contains large quantities of dissolved salts, especially sodium chloride, the electricity will be carried mainly by the ions of the latter salt. The discharged cl ion reacts with the sulphuretted liydrogen in the solution according to

$$
\mathrm{H}_{2} \mathrm{~S}+{ }_{2} \mathrm{Cl}=2 \mathrm{HCl}+\mathrm{S} \text {. }
$$

TheT other negative ions, for example the sulphuric acid and carbonic acid ions which carry a part of the electricity have the same effect as the chlorine ions. The discharged ions react with water producing nascent oxygen

$$
\begin{aligned}
& \mathrm{SO}_{4}+\mathrm{H}_{2} \mathrm{O}=\mathrm{H}_{2} \mathrm{SO}_{4}+\mathrm{O} \\
& \mathrm{CO}_{3}+\mathrm{H}_{2} \mathrm{O}=\mathrm{H}_{2} \mathrm{O}+\mathrm{CO}_{2}+\mathrm{O}
\end{aligned}
$$

and this nascent oxygen then reacts with the dissolved sulphuretted hydrogen or: alkaline sulphide.

$$
\begin{aligned}
& \mathrm{H}_{2} \mathrm{~S}+\mathrm{O}=\mathrm{H}_{2} \mathrm{O}+\mathrm{S} \\
& \mathrm{NaHS}+\mathrm{O}=\mathrm{NaOH}
\end{aligned}
$$

If the Beckwith :water contains the greater quantity of its sulphur combined as 'sulphide or rather as hydrosulphide, for the sulphur ion cols being so small, by taking up hydrogen with the production of the ions may carry part of the aurent in which positive electrode on according to

$$
2 \mathrm{HS}=\mathrm{H}_{2} \mathrm{~S}+\mathrm{S} \text {. }
$$

The effect of the current is therefore in all cases the production of free sulphur at the positive electrode.

With regard to the current density which is most suitable for the production of free sulphur at the positive pole, it may be said that the effect will be greatest with small anode density as far as the production of sulphur from the action of discharged chlorine, sulphuric acid, and carbonic acid ions is concerned. Large cturrent density at the anode would lead to the production chiefly of molecular chlorine and molecular oxygen.

On the other hand, large current density at the anode would be favourable to the separation of sulphur by the last process, namely, the inter action of SH ions. It is highly probable that the production of $S$ by the action of the discharged $\mathrm{Cl}, \mathrm{SO}_{4}$ and $\mathrm{CO}_{3}$ ions greatly preponderates, so that a low current density is favourable.

The strength of the current should probably not exceed 20 to 30 milliamperes. The current density at the cathode is of no essential

On account of its larger quantity of sulphur and its better-conducting power, the water of the Old Sulphur Well is perhaps preferable to the ect the for $r$ being alkaline, which appears to be of great

With regard to the current density which is most suitable for the production of free sulphur at the positive pole, I found that the effect was greatest with small anode density and Dr. Dawson confirms this, stating that the strength of the current should probably not exceed 20 to 30 milliampères:

The action of an electric current in the manner such as is used in the Harrogate Beckwith Bath would. probably be the only one which would give the exact conditions necessary to actually release the nascent sulphur on the exact surface on the patient's skin where it is required.

In the case of certain patients the sulphur is not deposited so visibly as on others; why, 1 cannot say.

Ordinary sulphur baths are used with.benefit at Harrogate in gout and rheumatism. I am, however, convinced that the benefit is much greater and quicker when electricity is used in the sulphur water. I am also persuaded that peripheral neuritis, neuralgia, and certain forms of paralysis do better when electricity is applied in sulphur water than in ordinary water or in blankets. I have come to this conclusion from observations upon seven or eight patients treated daily by both methods through the Harrogate "season."

I also believe that nascent sulphur enters the skin by means of the constant current when applied in sulphur water.
Conclusions.

1. That nascent sulphur is deposited in the Harrogate sulphur water by electricity at the positive pole.

2. That the same thing takes place on the skin of patients in a sulphur electric bath under similar circumstances. 3. That in addition to the remedial influence of nascent sulphur, electricity stimulates the peripheral nerves all over the body in a sulphur bath, and thus renders the action of sulphur more rapid and more efficacious in skin and gouty affections.

\section{AMPUTATION MORTALITY AT THE LONDON TEMPERANCE HOSPITAL.}

By W. J. COLLINS, M.S., M.D.; B.Sc.Jond., F.R.C.S., Surgeon to the London. Temperance Hospital, and to the Royal Eye Hospital.

THE following table, for which I am indebted to the Surgical Registrars, Messrs. Griffith and Hosford, includes all amputations performed by me at the London Temperance Hospital since I succeeded Mr. Pearce Gould as Surgeon to the Hospital on July Ist, I888, up to December 31st, I900.

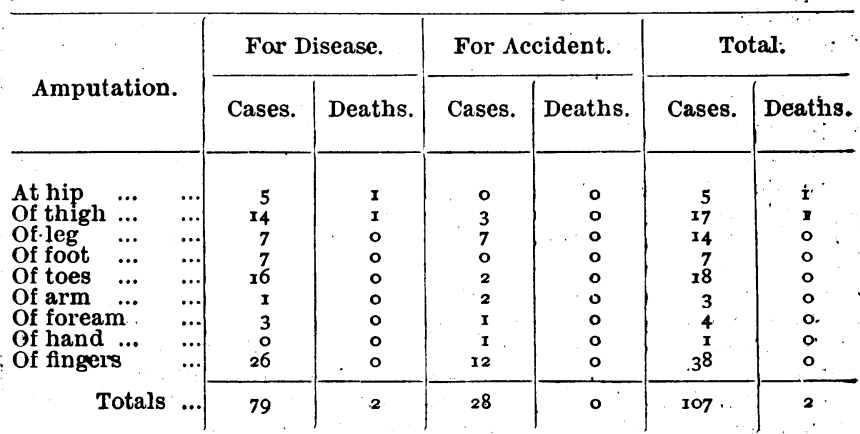

'inis gives a total of 107 cases, with 2 deaths. The ratal case of amputation at the hip was in a little girl aged 8, in the last stage of morbus coxæ, greatly emaciated, and suffering from advanced amyloid degeneration. The other fatal case was that of a man aged 49 , who post mortem was found to have sarcoma of the liver and in the pelvis, secondary to sarcoma in the ham, for which amputation of the thigh was performed. This latter was the only case for whom alcohol in any form was ordered.

\section{MEM OR ANDA}

MEDICAL, SURGICAL, OBSTETRICAL, THERAPEUTICAL, PATHOLOGICAL, ETC.

\section{ACUTE CASE OF PITYRIASIS RUBRA (DERMATITIS EXFOLIATIVA GENERALIS): RAPID RECOVERY.}

C., AGED 53, male, had been in poor health for some time, being especially "troubled with his breath." He was a tall stout man, rather flabby, with the well-marked dilated facial capillaries and the slight œdema about the lower extremities characteristic of a feebly-acting heart. : He had a mitral systolic murmur. His occupation was indoors, and his habits were fairly abstemious. After a slight cold eavly in July, 1900, his breathing became suddenly much worse and the cedema of the feet spread up to the knees. i The abdomen showed signs of corresponding passive effusion. Orthopnœa rapidly developed, and his urine contained a trace of albumen. His pulse was irregular and intermittent, and his temperature normal.

Rest was enjoined and light nutritious food admin istered, alcohol entirely stopped, and the following pre-

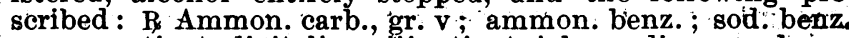
$\bar{a} \bar{a}$ gr. $x$; tinct. digitalis m ilj tinct. jaborandi, $\mathrm{m} x$; decoe.

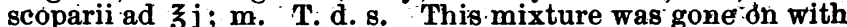
for three weeks, and at the end of that time the patient had quite recovered from the orthopnœa. All swelling had gone, 